\title{
Widespread exploitation of the honeybee by early Neolithic farmers
}

Mélanie Roffet-Salque*, Martine Regert, Richard P. Evershed, Alan K. Outram, Lucy J. E. Cramp, Orestes Decavallas, Julie Dunne, Pascale Gerbault, Simona Mileto, Sigrid Mirabaud, Mirva Pääkkönen, Jessica Smyth, Lucija Šoberl, Helen L. Whelton, et al.

\section{ABSTRACT}

The pressures on honeybee (Apis mellifera) populations, resulting from threats by modern pesticides, parasites, predators and diseases, have raised awareness of the economic importance and critical role this insect plays in agricultural societies across the globe. However, the association of humans with A. mellifera predates post-industrial-revolution agriculture, as evidenced by the widespread presence of ancient Egyptian bee iconography dating to the Old Kingdom (approximately 2400 BC). There are also indications of Stone Age people harvesting bee products; for example, honey hunting is interpreted from rock art in a prehistoric Holocene context and a beeswax find in a pre-agriculturalist site. However, when and where the regular association of A. mellifera with agriculturalists emerged is unknown. One of the major products of A. mellifera is beeswax, which is composed of a complex suite of lipids including $n$-alkanes, $n$-alkanoic acids and fatty acyl wax esters. The composition is highly constant as it is determined genetically through the insect's biochemistry. Thus, the chemical 'fingerprint' of beeswax provides a reliable basis for detecting this commodity in organic residues preserved at archaeological sites, which we now use to trace the exploitation by humans of A. mellifera temporally and spatially. Here we present secure identifications of beeswax in lipid residues preserved in pottery vessels of Neolithic Old World farmers. The geographical range of bee product exploitation is traced in Neolithic Europe, the Near East and North Africa, providing the palaeoecological range of honeybees during prehistory. Temporally, we demonstrate that bee products were exploited continuously, and probably extensively in some regions, at least from the seventh millennium cal BC, likely fulfilling a variety of technological and cultural functions. The close association of A. mellifera with Neolithic farming communities dates to the early onset of agriculture and may provide evidence for the beginnings of a domestication process.
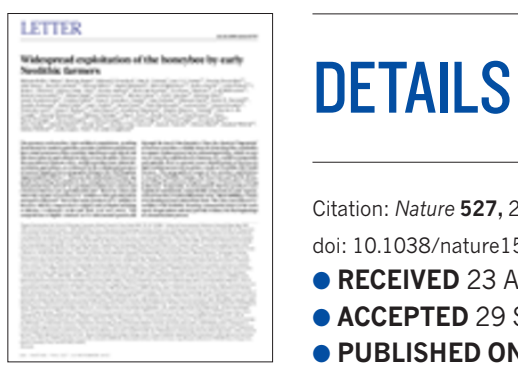

\section{SUMMARY}

Eurasian farmers have been using bee products for at least 9,000 years. Chemical traces of beeswax have been detected in ceramic potsherds dating back at least nine millennia, pointing to widespread exploitation of bee products by early farming societies in Europe, the Near East and North Africa. The northernmost limits to the natural ecological range of honeybees in prehistoric times are also revealed.

\section{The question}

Our study addresses two related questions. First, honeybees are crucial to modern agriculture, but when and where did a regular association between farmers and bees emerge ${ }^{1}$ ? Second, what were the ecological limits of the honeybee in prehistoric times? Answers to the first question have so far come largely from iconography, such as 4,400-year-old beekeeping scenes in ancient Egypt ${ }^{2}$ and stunning honey-hunting scenes in rock art at the Iberian Mediterranean Basin ; beeswax has also been identified in a pre-agriculturalist site in South Africa ${ }^{4}$. Discussion of the second question has been hampered by the lack of a fossil record from the past 11,000 years.

\section{The discovery}

Our method relies on the analysis of pottery from archaeological sites. Early agriculturalists used unglazed ceramic containers to store and process commodities, allowing lipid compounds in those commodities to become trapped in the clay pores of the containers. Although invisible to the naked eye, these compounds can be extracted and characterized by analytical techniques. One such commodity is beeswax, one of the two bee products that were probably exploited by early agriculturalists (of these, honey might have had culinary uses, whereas beeswax could have been used for lighting, as a plasticizer to soften brittle tree-resin adhesives, as a waterproofing agent for porous vessels, or in medicines and cosmetics). Honey is composed mainly of water-soluble sugars and does not survive in the archaeological record. But beeswax - which is composed of a suite of lipids - is largely hydrophobic and resists 
degradation. It also has a highly characteristic chemical 'fingerprint'.

Over the past 20 years, we have analysed some 6,400 clay pottery vessels from 150 Eurasian archaeological sites, dating between 7,000 BC and $2,000 \mathrm{BC}$, for the presence of lipids. Animal fats are the most common components, providing evidence for milk exploitation ${ }^{5,6}$ and cheesemaking ${ }^{7}$ in prehistory. Now, we have also detected the distinctive signature of beeswax in 75 potsherds from across Eurasia, demonstrating that early farmers were using beehive products at least 9,000 years ago. Notably, there is no evidence for the use of beeswax at sites in Scotland and Fennoscandia at this time, pointing to an ecological limit to the prehistoric occurrence of honeybees.

\section{The implications}

Our analyses of archaeological potsherds allow the presence of beeswax - and thus of the honeybee - to be traced across Europe, the Near East and North Africa, providing a palaeoecological map of the insect's range that is not available from the fossil record. The results reveal that an association between honeybees and farming communities had developed as early as the seventh millennium BC. However, an unanswered question is whether beehive products were obtained through honey-hunting or through apiculture at these early times. Unequivocal evidence for apiculture does not appear until much later ${ }^{8}$, with the earliest artificial beehives (hollow clay cylinders), found in an apiary from an Iron Age city in the Jordan valley, dating to the tenth to ninth centuries BC.

Finally, our study relied on the analysis of prehistoric pots, but it is likely that the human exploitation of bees predates pot-making and agriculture. As yet, however, there is no widespread and reliable evidence for such exploitation.

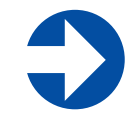

The full version of the original article is on Nature's website at go.nature.com/2pgkkzm

\section{GRAPHICAL ABSTRACT}
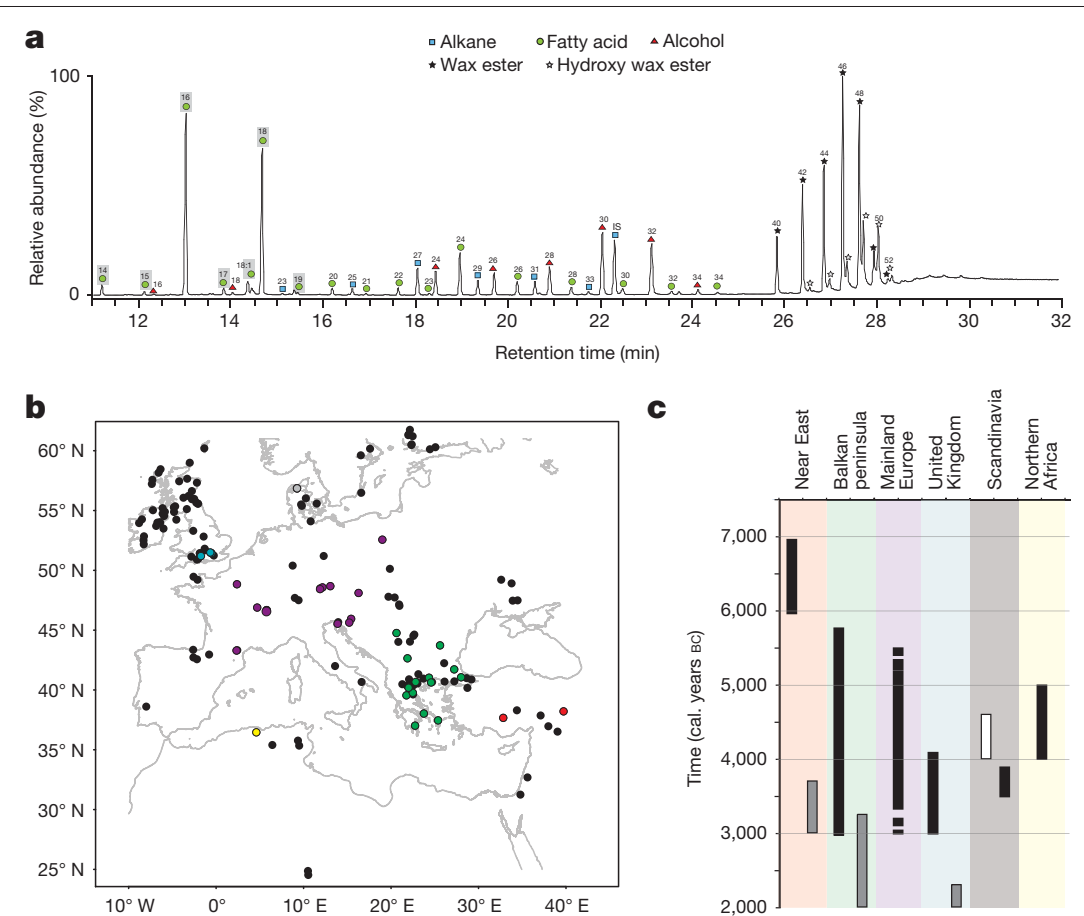

Prehistoric distribution of beeswax. a, The chemical 'fingerprint', revealed by gas chromatography, of degraded beeswax (mixed with animal fat) detected in a potsherd from Turkey $(6,500-6,000 \mathrm{cal}$. BC). The fingerprint comprises alkanes, fatty acids, alcohols, wax esters and hydroxy wax esters. b, Geographical distribution of the archaeological sites investigated here. The sites indicated with coloured dots yielded traces of beeswax in potsherds. No beeswax was detected at the sites indicated with black dots. (The colours of the dots match the shading used for different regions in c.) $\mathbf{c}$, Chronology of beeswax use across Eurasia. Black indicates Neolithic (farming) contexts; white denotes pre-Neolithic (hunter-gatherer) contexts; dark grey indicates Bronze Age contexts.

\section{FURTHER READING}

1. Larson, G. \& Fuller, D. Q. The evolution of animal domestication. Annu. Rev. Ecol. Evol. Syst. 45, 115-136 (2014).

A review of the history of the domestication of animals, including bees.

2. Crane, E. The World History of Beekeeping and Honey Hunting (Duckworth, 1999). An exploration of the global history of human use of bees from prehistoric times to today.

3. Dams, M. \& Dams, L. R. Spanish rock art depicting honey gathering during the Mesolithic. Nature 268, 228-230 (1977). Iconographic evidence for honey-hunting in Spain from $8,000 \mathrm{BC}$ to $2,000 \mathrm{BC}$.

4. d'Errico, F. et al. Early evidence of San material culture represented by organic artifacts from Border Cave, South Africa. Proc. Natl Acad. Sci. USA 109, 13214-13219 (2012). Identification of a 40,000-year-old lump of beeswax in a South African cave.

5. Evershed, R. P. et al. Earliest date for milk use in the Near East and southeastern Europe linked to cattle herding. Nature 455, 528-531 (2008).

The identification of milk fats preserved in potsherds reveals that milk was in use by the seventh millennium $B C$.

6. Dunne, J. et al. First dairying in green Saharan Africa in the fifth millennium BC. Nature $\mathbf{4 8 6}$, 390-394 (2012).

This discovery of milk fats in potsherds shows that prehistoric Saharan people were exploiting milk.

7. Salque, M. et al. Earliest evidence for cheese making in the sixth millennium $\mathrm{BC}$ in northern Europe. Nature 493, 522-525 (2013). Milk fats are found preserved in perforated vessels - evidence for cheese-making in prehistoric Poland.

8. Mazar, A., Namdar, D., Panitz-Cohen, N., Neumann, R. \& Weiner, S. Iron Age beehives at Tel Rehov in the Jordan valley. Antiquity $\mathbf{8 2}$ 629-639 (2008)

Evidence for prehistoric beekeeping: an apiary comprising about 100 beehives.

\section{RELATED CONTENT}

\author{
Early farmers minded their own beeswax \\ Ewen Callaway \\ go.nature.com/1xadfif
}

Humans have relied on honeybees for nearly 9000 years - and now they're mysteriously declining

Chelsea Harvey

go.nature.com/1xae5w3

Clay fragments suggest how long we've been relying on honeybees

Maryn McKenna

go.nature.com/1rxecr1 